
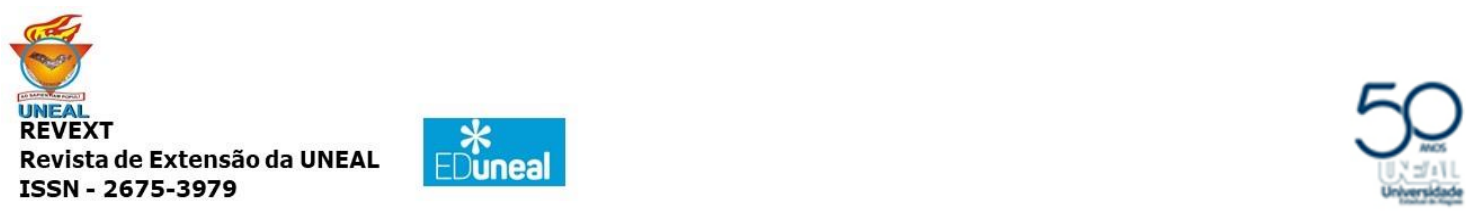

Ano 6, Vol. 6 (2), no 2. 2021, julho/dezembro de 2021. https://doi.org/10.48179/revext.v6i2.314

\title{
Material didático complementar para o ensino básico e superior: construção de maquete através de biscuit
}

\author{
${ }^{1}$ Mariana dos Santos; ${ }^{2}$ Josefa Eleusa da Rocha
}

1ORCID: https://orcid.org/0000-0002-1847-1463;_Universidade Estadual de Alagoas-UNEAL. Graduanda do Curso de Licenciatura em Ciências Biológicas, Email: marianaadossaantos7@ gmail.com; 2ORCID: https://orcid.org/0000-0001-8175-1305; Docente do Curso de Licenciatura em Ciências Biológicas-UNEAL. E-mail: : eleusa.rocha@uneal.edu.br

Resumo - Com este estudo, objetivou-se construir material didático complementar, através de biscuit. Trata-se de um trabalho desenvolvido pela acadêmica do curso Licenciatura em Ciências Biológicas da Universidade Estadual de Alagoas - UNEAL. Para tanto, foi escolhido um modelo evidenciando a anatomia do sistema de ductos biliares, foi utilizado os seguintes materiais: $2 \mathrm{~kg}$ de massa de biscuit, 1 placa de madeira (40x60), 3 cartolinas vermelhas, 1 pistola de cola quente, 2 tubos de cola quente, 4 tintas de tecido e 1 pincel. Primeiramente, utilizou-se a placa de madeira (40x60), onde foi recoberta com a cartolina vermelha, a mesma foi usada como base para fixar as estruturas do sistema de ductos biliares. Para a confecção das estruturas anatômicas, foi utilizado a massa de biscuit e para tingir as peças usou-se tintas de tecido nas cores: vinho, verde, amarelo e bege. Os ductos biliares são vias de ductos encarregados de transportar a bile até a vesícula biliar, onde a secreção se armazena e, posteriormente segue até o intestino delgado e exerce a sua ação digestiva. Os resultados da construção da maquete foram satisfatórios, foi possível observar todos os órgãos que estão relacionados ao sistema de ductos biliares (ducto hepático direito e esquerdo, comum, cístico, colédoco e pancreático). O que permite concluir que, a produção de maquete constituiu-se como um instrumento didático prático proveitoso tanto no ensino básico quanto superior, uma vez que, permite que os discentes possam relacionar conteúdos teóricos através de material didático complementar produzido a partir de biscuit.

Palavras-chave: Ductos biliares; Biscuit; Material didático.

Abstract - With this study, the objective was to build complementary teaching material, through biscuit. It is a work developed by the academic of the Licentiate Degree in Biological Sciences at the State University of Alagoas - UNEAL. For this, a model was chosen showing the anatomy of the bile duct system, using the following materials: $2 \mathrm{~kg}$ of biscuit dough, 1 wooden board (40x60), three red cardboards, one hot glue gun, 2 tubes. Hot glue, four fabric paints and one brush. First, a wooden board (40x60) was used, where it was covered with red cardboard, which was used as a base to fix the structures of the bile duct system. To make the anatomical structures, biscuit dough was used and to dye the pieces fabric dyes were used in the colors: wine, green, yellow and beige. The bile ducts are duct pathways responsible for 

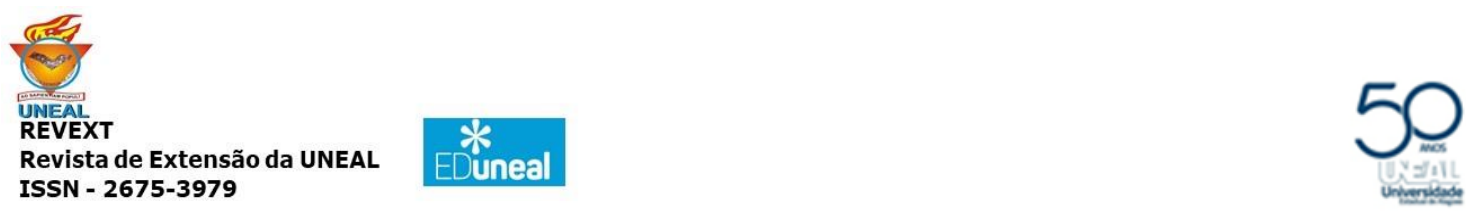

Ano 6, Vol. 6 (2), no 2. 2021, julho/dezembro de 2021. https://doi.org/10.48179/revext.v6i2.314

transporting bile to the gallbladder, where the secretion is stored and, later, goes to the small intestine and exerts its digestive action. The results of the construction of the model were satisfactory, it was possible to observe all the organs that are related to the bile duct system (right and left hepatic duct, common, cystic, common and pancreatic). Which allows us to conclude that, the production of mockup was constituted as a useful practical teaching tool in both basic and higher education, since it allows students to relate theoretical content through complementary teaching material produced from biscuit.

Keywords: Bile ducts; Biscuit; Courseware.

\section{Introdução}

Materiais didáticos são ferramentas essenciais e importantes utilizadas pelos professores como forma de facilitar a aprendizagem dos alunos, ou seja, é tudo aquilo que o professor utiliza em sala de aula para auxiliar na compreensão do conteúdo. Nos dias atuais é muito difícil construir uma aula sem esses recursos, pois a medida em que a sociedade se moderniza o professor e todo o espaço escolar deve acompanhar essa modernização também (SANTOS; SANTANA, 2017).

No Brasil, o nível da educação escolar compreende a educação infantil, o ensino fundamental e o ensino médio. Além da educação básica, o outro nível escolar do sistema educacional brasileiro é a educação superior. O conceito de educação básica foi ampliado a partir da Lei de Diretrizes e Bases da Educação (LDB), de 1996, pois a lei anterior estabelecia como básico o ensino chamado de primeiro grau. De acordo com a LDB, "a educação básica tem por finalidades desenvolver o educando, assegurar-lhe a formação comum indispensável para o exercício da cidadania e fornecer-lhe meios para progredir no trabalho e em estudos posteriores (MENEZES, 2010).

Por isto, a elaboração de atividades teórico-práticas criadas a partir de construções material didático complementar, agem como instrumento para tornar o ensino de ciências mais criativo e dinâmico, possibilitando aos discentes, através de observações e análise, construir seu conhecimento de forma mais concreta (BOTELHO, 2008).

Considerando a carência de aulas práticas e de materiais didático particularmente nas áreas das ciências humanas, no ensino básico e superior, objetivou-se a construção de material didático complementar produzido apartir de biscuit, uma vez que, materiais didáticos complementar/alternativos contribuiem para a melhoria e qualidade do ensino.

\section{Metodologia}

Trata-se de um trabalho desenvolvido pela acadêmica do curso Licenciatura em Ciências Biológicas da Universidade Estadual de Alagoas - UNEAL. Para tanto, foi escolhido 


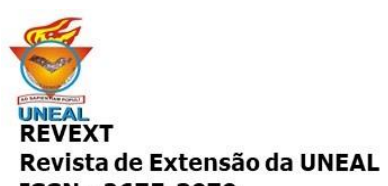

ISSN - 2675-3979

Ano 6, Vol. 6 (2), n 2. 2021, julho/dezembro de 2021. https://doi.org/10.48179/revext.v6i2.314 para construir um modelo evidenciando a anatomia do sistema de ductos biliares, juntamente com orgãos que estão anexos ao mesmo, utilizando o seguintes materiais: $2 \mathrm{~kg}$ de massa de biscuit, 1 placa de madeira (40x60), 3 cartolinas vermelhas, 1 pistola de cola quente, 2 tubos de cola quente, 4 tintas de tecido e 1 pincel.

Primeiramente, utilizou-se a placa de madeira (40x60), onde foi recoberta com a cartolina vermelha, a mesma foi usada como base para fixar as estruturas do sistema de ductos biliares. Para a confecção das estruturas anatômicas, foi utilizado a massa de biscuit e para tingir as peças usou-se tintas de tecido nas cores: vinho, verde, amarelo e bege (figura 1).

Figura 1- Materiais utilizados para a construção da maquete. 1 massa de biscuit; 2 tintas de tecido; 3 placa de madeira; 4 cartolina vermelha; 5 bastões de cola quente; 6 pistola de cola quente; 7 pincel.

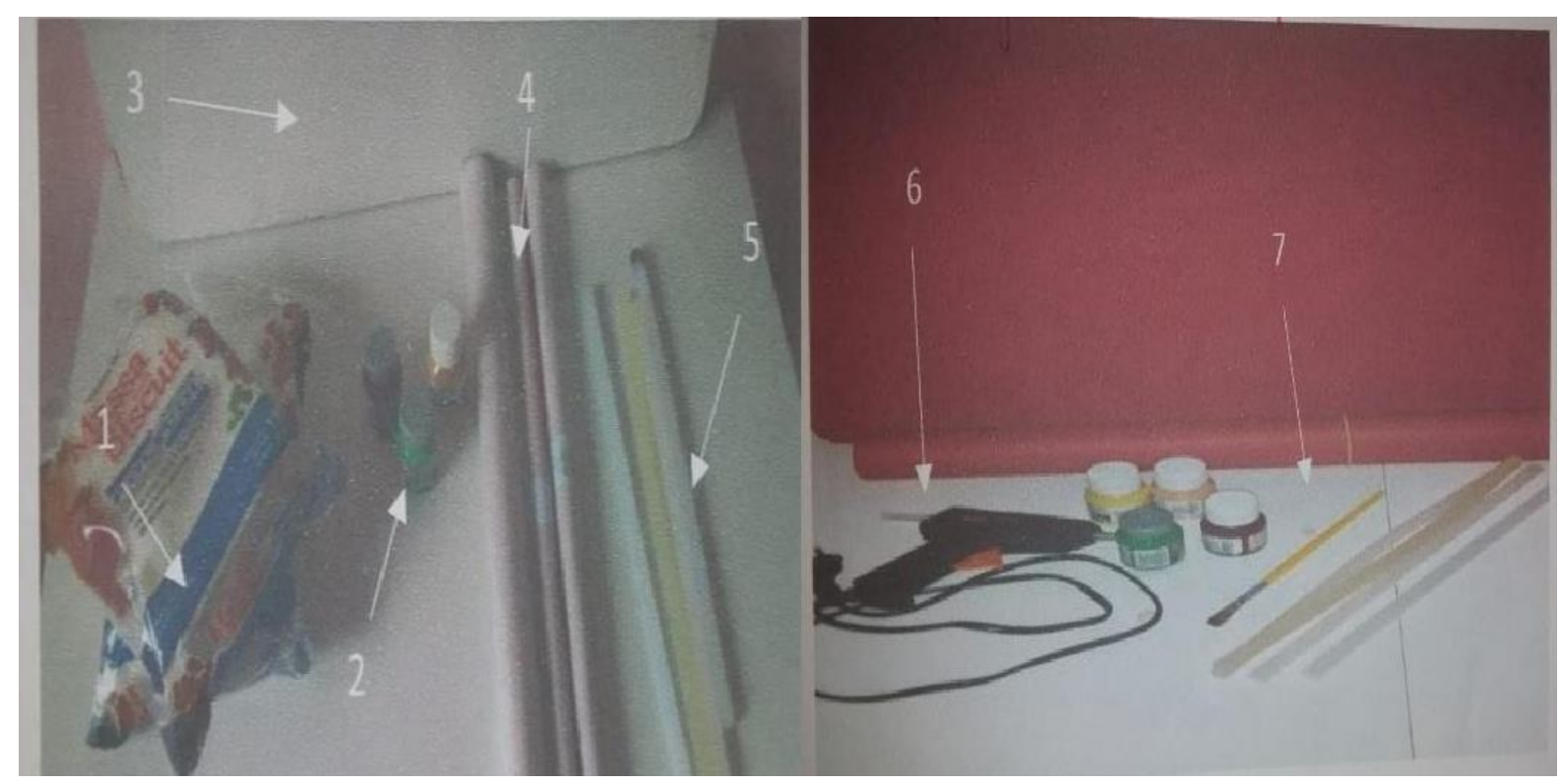

Fonte: arquivo pessoal.

Em seguida, já com a massa tingida, foi produzido os modelos com os seguintes órgãos: fígado, pâncreas, ductos biliares, vesícula biliar e primeira porção do duodeno, conforme a (figura 2) abaixo, vejamos o modelo do fígado. 


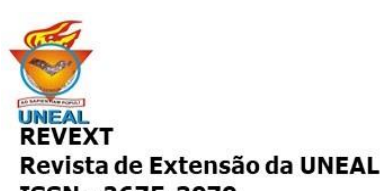

ISSN - 2675-3979

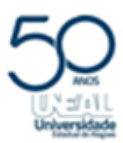

Ano 6, Vol. 6 (2), no 2. 2021, julho/dezembro de 2021. https://doi.org/10.48179/revext.v6i2.314

Figura 2- (1) Modelo anatômico do fígado feito com massa de biscuit.

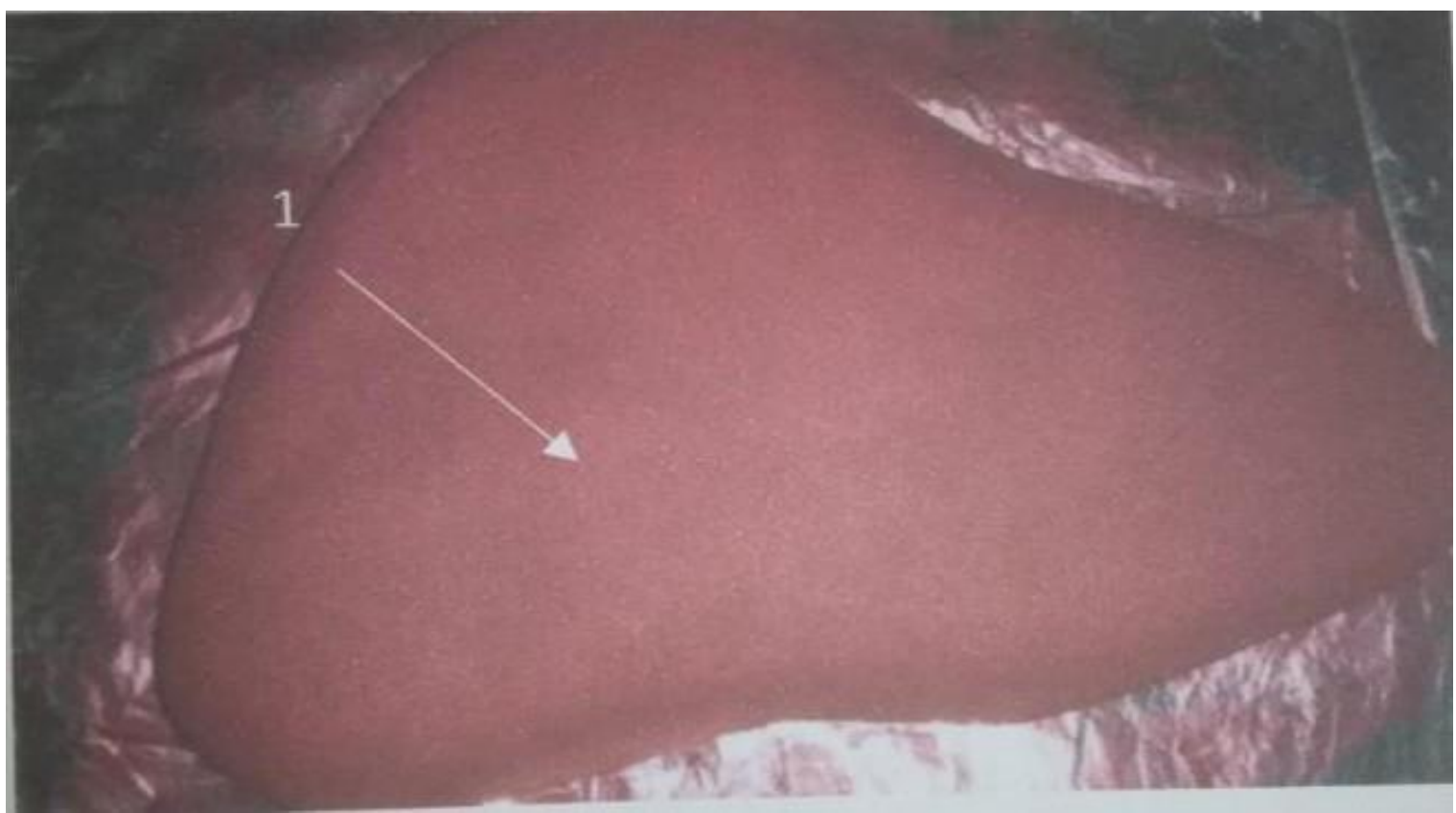

Fonte: arquivo pessoal.

Logo após, foi preciso deixar secar as peças em cima de bolsas plásticas por no mínimo 3 dias, em um local arejado até que estivessem totalmente secas. Concluída a confecção dos órgãos, seguiu-se para a parte final do modelo, utilizou-se a madeira como base e por fim, as peças foram coladas com cola quente na base de madeira.

\section{Resultados e Discussão}

Não há como participar ativamente de uma sociedade como agente de transformação sem o domínio da cultura científica e prática. Da mesma forma, sabe-se que o domínio da cultura científica e prática é resultante da relação estabelecida entre o aluno e o objeto de estudo, que pode ser mediada com o uso de recursos alternativos, a fim de tornar o conteúdo o mais significativo possível (POLICARPO; STEINLE, 2017).

O processo educativo constantemente transforma-se e apesar das diversas tentativas de implementação de materiais para apoio didático, parte do ensino ainda utiliza a exposição oral e memorização de informações como principal metodologia. Logo, um dos maiores desafios educacionais está na utilização de métodos que efetivamente culminem na aprendizagem, não apenas em uma experiência meramente conceitual (CARMO et al., 2019).

$\mathrm{Na}$ interação em sala de aula, percebe-se que alguns alunos possuem um ritmo de 

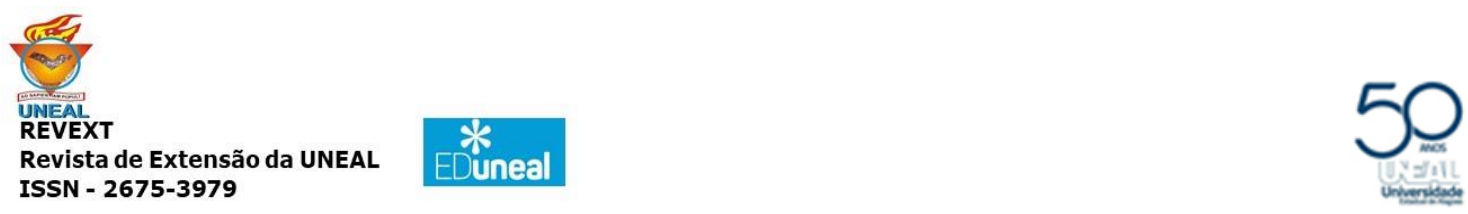

Ano 6, Vol. 6 (2), no 2. 2021, julho/dezembro de 2021.

https://doi.org/10.48179/revext.v6i2.314

aprendizado diferenciado dos demais colegas, passamos a observá-lo com uma atenção especial, tais observações se atentam principalmente nas dificuldades de leitura e escrita, no raciocínio lógico para o processamento de uma informação, na dificuldade de compreensão de um conceito científico mais complexo, como também em estabelecer relações entre o conteúdo estudado e a realidade vivida, nessas situações costumamos dizer que o aluno tem dificuldades de aprendizagem, tais constatações se refletem também nos resultados avaliativos, expressando-se com notas ou conceitos bem abaixo do desejado (CAPORRINO; XIMENES, 2010).

Sabemos que existem dificuldades em sala de aula, tanto dos professores ao ensinar quanto aos alunos em aprender, se tornando muitas vezes um trabalho árduo entre ambas às partes, um problema muito comum que todo docente enfrenta em sala de aula. Diante disso começou a se pensar em meios de facilitar esse ensino por parte do professor facilitando a aprendizagem do aluno, tornando então assim o ensino aprendizagem mais significativo. Os materiais didáticos de modo geral, funcionam como grandes métodos facilitadores de aprendizagem (RODRIGUES et al., 2020).

A base de uma sociedade é a educação, e é atribuído a ela o desenvolvimento de um país, e no Brasil, assim como na maioria dos países, encontra-se ainda muito defasada. Nesse contexto, muito se tem debatido sobre tais dificuldades relacionadas à pratica docente no contexto escolar. As pesquisas na área da educação apontam a falta de material, infraestrutura, e desmotivação como principais fatores para o declínio educacional (TOKUYOCHI et al, 2008).

O material didático quando usado com o auxílio do professor em sala de aula, facilita a aprendizagem do aluno e pode alcançar o objetivo do professor, mas para que isso ocorra é preciso saber usá-lo de forma coerente com a aula e de acordo com a necessidade do educando. Os educadores precisam construir conhecimentos com os alunos, sempre uma análise sobre quais materiais didáticos são mais indicados aos discentes e quais que eles se adaptam melhor (GARCIA, 2014).

De acordo com uma das competências da Base Nacional Comum Curricular (BNCC) é necessário e importante estimular o desenvolvimento das capacidades do aluno seja através da observação, memória, investigação, imaginação ou análise crítica para que assim, possa-se chegar no processo de abstração e aprendizagem (BRASIL, 2018).

A utilização de ferramentas práticas ou de instrumentos complementares nas aulas, auxilia na concretização da aprendizagem por permitir que o discente se envolva ativamente em todo o processo (CONSTANTE; VASCONCELOS, 2010).

Os resultados da construção da maquete foram satisfatórios, foi possível observar todos os órgãos que estão relacionados ao sistema de ductos biliares (ducto hepático direito e esquerdo, comum, cístico, colédoco e pancreático) como ilustra a (figura 3), percebeu-se também, que é possível construir peças didáticas anatômicas com massa de biscuit a baixo custo. 


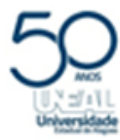

Ano 6, Vol. 6 (2), no 2. 2021, julho/dezembro de 2021. https://doi.org/10.48179/revext.v6i2.314

Figura 3- Maquete concluída. 1 Ductos biliares; 2 Vesícula biliar; 3 Fígado; 4 Parte do duodeno; 5 Pâncreas; 6 Ducto pancreático.

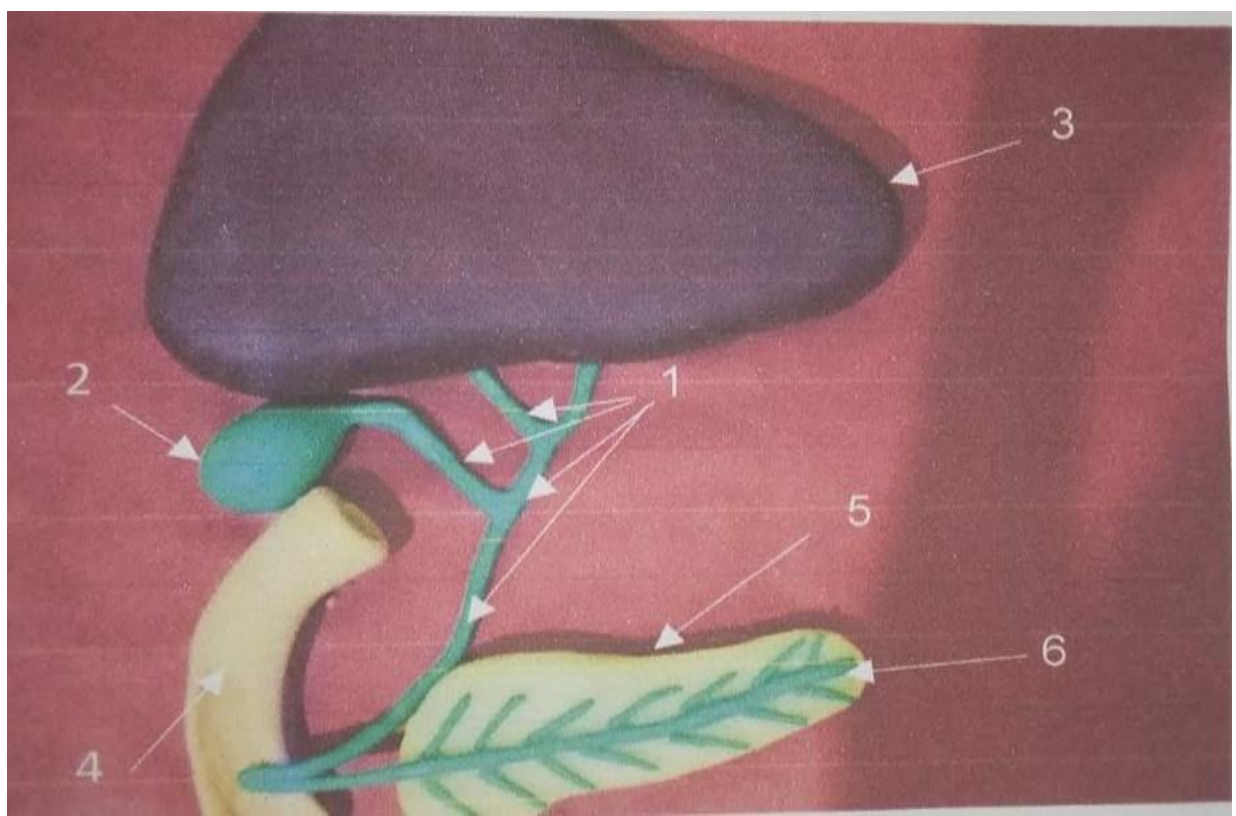

Fonte: arquivo pessoal.

Diversos estudos observaram que, dentre os materiais utilizados, a massa de biscuit é a mais apropriada para a preparação de modelos pois, mostra uma grande resistência e duração podendo ser manuseados frequentemente sem se deformar (MATOS et al, 2009). É preciso possibilitar ao aluno diferentes estratégias de aprendizagem de modo que se possa despertar o desejo de produzir, refletir e questionar os conteúdos apresentados em sala de aula (BASTOS; FARIA, 2011).

Segundo Silva (2014), a aplicação de cores para a preparação de peças didáticas também é outro fator que instiga visualmente o aluno, além de auxiliar também no processo de memorização das estruturas. o que permite dizer que é um método facilitador de aprendizagem. É importante ressaltar que a partir de metodologias diferenciadas, que são desenvolvidos em aulas práticas, a construção do conhecimento torna-se mais produtivo e atrativo, facilitando assim a compreensão do educando (SOARES; BAIOTTO, 2015). 


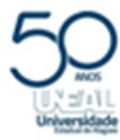

Ano 6, Vol. 6 (2), no 2. 2021, julho/dezembro de 2021. https://doi.org/10.48179/revext.v6i2.314

Autores como Costa e Lins (2012) alegam que, a elaboração de material alternativo é de total relevância para facilitar a compreensão dos conteúdos abordados seja no ensino básico ou superior, já que a falta de laboratórios adequados para as aulas práticas em especial as areas das Ciências humanas ainda é um problema muito presente. Corroborando com a ideia de Costa e Lins (2012), na qual destaca que, há uma carência de peças cadavéricas, Justina (2006), enfatiza que é possível suprir esta carência de material cadavérico a partir da produção de modelos anatômicos feito com massa de biscuit, pois segundo ele a utilização do mesmo forma estruturas próximas as do corpo humano.

Fica evidente a importância de se utilizar recursos didáticos que chamem a atenção dos alunos, diante dos fatos explanados, é fundamental que o professor em suas aulas sempre procure métodos de aprendizagem inovadores, tentando achar maneiras que façam os alunos entenderem os assuntos de maneira prazerosa e assim, facilitar a aprendizagem (FERREIRA et al., 2013).

\section{Conclusão}

O processo de ensino torna-se a cada dia desafiador, principalmente levando em consideração o cenário que a educação vem enfrentando causado pela pandemia da Covid-19. Procurar meios e materiais complementares para estimular e despertar o interesse dos alunos diante desse contexto é essencial no processo de aprendizagem.

Fica perceptível que a produção de maquete constituiu-se como um instrumento didático prático e proveitoso, tanto para o ensino básico quanto superior, uma vez que, permite que os discentes possam relacionar conteúdos teóricos através de material didático prático complementar produzido a partir de biscuit. Conclui-se que, está produção é um método eficiente para o ensino em especial nas disciplinas de ciências humanas.

\section{Referências bibliográficas}

BRASIL, Ministério da Educação. Base Nacional Comum Curricular. Educação é a base ensino médio. Brasília, 2018.

BASTOS, K. M.; FARIA, J. C. N. DE M. Aplicação de modelos didáticos para abordagem da célula animal e vegetal, um estudo de caso. Enciclopédia Biosfera, Centro Científico Conhecer, v. 7, n. 13, p. 1867-1877, 2011. 


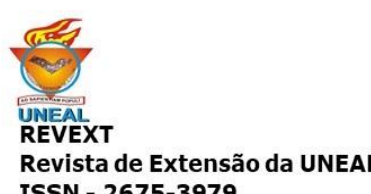

ISSN - 2675-3979

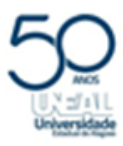

Ano 6, Vol. 6 (2), no 2. 2021, julho/dezembro de 2021. https://doi.org/10.48179/revext.v6i2.314

BOTELHO, L. A. O terrário como instrumento organizador da aprendizagem em Ciências do $9^{\circ}$ ano. Programa de Desenvolvimento Educacional-PDE. Curitiba, 2008.

CAPORRINO, C. G; XIMENES, M. L. D. Materiais didático-pedagógicos como recurso de aprendizagem para alunos com necessidades educativas especiais: caminhos e possibilidades. O professor PDE e os desafios da escola pública Paranaense. Universidade Estadual do Norte do Paraná - UENP, 2010.

CARMO, E. P. M; ARAÚJO, J. P; CORRÊA, M. A; LEITE, D. C. Oficinas pedagógicas: estratégias para o ensino de educação ambiental em Cametá-PA. Ciências em Foco, v.12, n.1, p.14-24, 2019.

COSTA, G. B. F; LINS, C. C. C. A. O cadáver no ensino da anatomia humana: uma visão metodológica e bioética. Revista brasileira de educação médica. Pernambuco, v. 36. n. 3. p. 369-376, 2012.

CONSTANTE, A; VASCONCELOS; C. Atividades lúdico-práticas no ensino de geologia: complemento motivacional para a aprendizagem. Terrae Didática, v. 6, n. 2, 2010.

FERREIRA, P. M. P. et al. Avaliação da importância de modelos no ensino de biologia através da aplicação de um modelo demonstrativo da junção intercelular desmossomo. Revista Brasileira de Biociências, v. 11, n. 4, p. 388-394, 2013.

GARCIA, Tânia Braga. Materiais didáticos são mediadores entre professor, alunos e o conhecimento, 2014. Disponível em: < http://portaldoprofessor.mec.gov.br/. Aacesso em: 09 out. 2021.

JUSTINA, L. A. D. Utilização de modelos didáticos no ensino de genética: exemplo de representação de compactação do DNA, eucarioto. Mundi. v. 10. n 2. p. 47-54, 2014.

MATOS, C. H. C. et al. Utilização de modelos didáticos no ensino de entomologia. Revista de biologia e ciências da terra. v 9, n 1. p. 19-23, 2009.

MENEZES, E. T. Verbete educação básica. Dicionário Interativo da Educação BrasileiraEducaBrasil. São Paulo: Midiamix Editora, 2010. Disponível em <https://www.educabrasil.com.br/educacao-basica/>. Acesso em: 05 out. 2021.

POLICARPO, I; STEINLE, M. C. B. Contribuições dos recursos alternativos para a prática pedagógica. 2017.

RODRIGUES, A. I; CARDOSO, D. S. F; NOBRE, R. F; OLIVEIRA, P. F. A importância do uso do material didático como apoio em sala de aula, facilitando á aprendizagem no ensino 


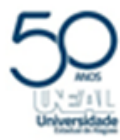

Ano 6, Vol. 6 (2), no 2. 2021, julho/dezembro de 2021. https://doi.org/10.48179/revext.v6i2.314

fundamental. Instituto Saber de Ciências Integradas - Revista Científica. v 8, n 3, p 4, 2020.

SANTOS, I; SANTANA, W. Estratégias de aprendizagem: A utilizaçao da maquete no ensino de história. X Encontro de Formação de Professores-ENFOPE, ISSN: 2179-0663, 2017.

SILVA. J. A. O uso do biscuit como ferramenta complementar do ensino de anatomia humana: um relato de extensão universitária. Revista ciência extensão. v 10, n. 2. p. 35-40, 2006.

SOARES, R. M.; BAIOTTO, C. R. Aulas Práticas de Biologia: Suas Aplicações e o Contraponto desta Prática. ISSN 2316-4034, v 4- nº 2, 2015.

TOKUYOCHI, J. H; ANTUNES, F. H; BIGOTTI, S; CERENCIO, M; DANTAS, L. E. P; MARCOS, H. L; SOUZA, E. Retrato dos professores de Educação Física das escolas estaduais do estado de São Paulo. Revista Motriz, Rio Claro, v.14, n.4, p.418-428, 2008. 